\title{
Reducing Children's Negative Emotional States through Physical Education and Sport in Disaster-Prone Areas
}

\author{
Soni Nopembri ${ }^{1,2}$, Saryono ${ }^{1}$, Yoshio Sugiyama ${ }^{3}$ \\ ${ }^{1}$ Faculty of Sports Sciences, Yogyakarta State University, Yogyakarta, Indonesia \\ ${ }^{2}$ Graduate School of Human-Environment Studies, Kyushu University, Fukuoka, Japan \\ ${ }^{3}$ Faculty of Human-Environment Studies, Kyushu University, Fukuoka, Japan \\ Email: soni_nopembri@uny.ac.id, soni.nopembri@gmail.com
}

Received 5 November 2015; accepted 1 February 2016; published 4 February 2016

Copyright (C) 2016 by authors and Scientific Research Publishing Inc.

This work is licensed under the Creative Commons Attribution International License (CC BY). http://creativecommons.org/licenses/by/4.0/

(c) (i) Open Access

\begin{abstract}
The current study examined the effects of physical education (PE) and sports programs in reducing children's negative emotional states in disaster-prone areas near the Merapi volcano peak in Indonesia. Participants were 15 physical education and sports teachers, and 810 fourth through sixth grade students at elementary schools. Classes were randomly assigned to intervention and first and second control groups. The intervention group received a specially designed $P E$ and sports program using therapeutic psychosocial practices. The first and second control groups completed the pre-existing PE and sports programs over 28 weeks during the 2014-2015 academic years. Negative emotional states were measured by administering the Depression, Anxiety, and Stress Scales (DASS 42) before and after the education programs. A repeated measures analysis of variance showed significant differences between intervention and control groups.
\end{abstract}

\section{Keywords}

PE, Program, Psychological, Disaster, Student

\section{Introduction}

Indonesia has experienced several volcanic eruption disasters, such as Merapi in 2010, Sinabung in 2013, and Kelud in 2014. The slopes of Indonesia's 130 active volcanoes have been densely populated for thousands of years. Volcanic eruptions have occurred often, and the Merapi volcano is active. Merapi is located between Central Java and Yogyakarta, Indonesia, and attracts many researchers from around the world (Lavigne, et al., 2008). The last and largest eruption of Merapi occurred in 2010 and greatly affected both the physical and psy-

How to cite this paper: Nopembri, S., Saryono, \& Sugiyama, Y. (2016). Reducing Children's Negative Emotional States through Physical Education and Sport in Disaster-Prone Areas. Advances in Physical Education, 6, 10-18.

http://dx.doi.org/10.4236/ape.2016.61002 
chological states of human victims, particularly children.

The impact of disasters on humans is not only physical but also psychological. Natural disasters have caused extensive loss and damage to psychological wellbeing, the economy, and society (Jogia, Kulatunga, Yates, \& Wedawatta, 2014). Extensive loss of life, damage of physical facilities, and impact on socio-economic conditions are caused by natural disasters (Jogia, Kulatunga, Yates, \& Wedawatta, 2014; Yonekura, Ueno, \& Iwanaka, 2013). A natural disaster becomes a large-scale environmental stressor for a community because it happens suddenly, unexpectedly, and extensively damages live (Aslam \& Tariq, 2010).

The psychological impact is more visible after some occurrences of natural disasters, for example, earthquakes, tsunamis, floods, fires, hurricanes, typhoons, and volcanic eruptions. The damaging natural disaster always leads to psychological impact (Jogia, Kulatunga, Yates, \& Wedawatta, 2014; Mondal, et al., 2013). Furthermore, survivors who are affected socially, economically, and psychologically may change their behaviors after a disaster (Jogia, Kulatunga, Yates, \& Wedawatta, 2014). Some individuals may show permanent psychological symptoms after experiencing disaster (Aslam \& Tariq, 2010). Research results have shown that levels of general psychological distress are visible at 12 months and that post-traumatic stress reactions may continue until 18 months after a disaster (Aslam \& Tariq, 2010). Ronholt, Karsberg, \& Elklit (2013) have emphasized that disasters affect whole societies, especially a negative psychological impact on children.

Many studies have examined the psychological impact of the disaster on children. The psychological impact on children of both natural and manmade disasters is not always be recognized by parents (Mondal, et al., 2013). Secondary traumatization to the entire family can occur (Kilic, Ozguven, \& Sayil, 2003). Uemoto, Asakawa, Takamiya, Asakawa, \& Inui (2012) find that severe fear, anxiety, depression or physical symptoms are found in family members after earthquakes. Mondal, et al. (2013) show that loss of family members, structural devastation, or a fear response results in emotional deterioration for children and that stress symptoms begin to appear immediately. Children manifest trauma through psychological and behavioral changes, and often go unidentified (Kar, 2009). Exposures to individuals suffering injuries, those who are dying or dead, are common occurrences after a disaster strikes (Ronholt, Karsberg, \& Elklit, 2013). On the other hand, sometimes the effect of a disaster on the mental health of children is indecipherable (Uemoto, Asakawa, Takamiya, Asakawa, \& Inui, 2012). A child's developmental stage of cognitive and emotional maturity and use of coping strategies determines his/her psychological reactions to disaster (Kar, 2009). Meeting a child's needs is dependent on others, both during and after a disaster (Yonekura, Ueno, \& Iwanaka, 2013). Children who have lost their parents in a disaster need social support and mental health over the long term, and need comprehensive intervention and psychological support afterwards (Uemoto, Asakawa, Takamiya, Asakawa, \& Inui, 2012).

Physical education (PE) and sports can serve as a psychological intervention. PE and sports are typically the only disciplines within a school's curriculum that address problems relating to the physical and psychological health of students (Curelaru, Abalasei, \& Cristea, 2011). Health-related PE approaches may improve the psychosocial benefits for children in community health programs (Piko \& Keresztes, 2006). Therefore, physical activity has an important role in the psychological wellbeing of a student (Piko \& Keresztes, 2006). Sports and play activities can assist youth to non-verbally access, express, and resolve a myriad of troubling issues (Henley, 2005). The opportunity to learn new problem-solving skills, manage emotions, and behavior, and form healthy relationships is provided through sports and play programs (Henley, Schweitzer, de Gara, \& Vetter, 2007). Children can express difficult or painful emotions, wishes, fears, concerns, and fantasies, both verbally and nonverbally through play. Reenactment of traumatic experiences may also surface during play (Kar, 2009).

The impact of PE and sports programs with regard to a child's character development or affective status in Indonesian school settings has been studied (Mutohir, 2015), however, the use of similar programs to reduce the psychological effects of volcano disasters has not been studied in Indonesia. The present study aims to investigate a PE and sports program based on psychosocial education for children affected by the Merapi volcano disaster in Yogyakarta and evaluate its effects on negative emotional states (depression, anxiety, and stress). We will also compare these results to control groups of children who receive an unmodified PE and Sports program. We hypothesize that children's negative emotional states will reduce as a result of receiving the psychosocial-based PE and Sports programs.

\section{Method}

\subsection{Participants}

The fifteen elementary schools in disaster-prone areas 5 - $15 \mathrm{~km}$ from the top of the Merapi volcano were ran- 
domly organized into an intervention group and two control groups. School determination can be done randomly in the interventions program (Ronan \& Johnson, 1999). Fifteen PE and sports teachers and 810 fourth through sixth grade students (440 girls and 370 boys) enrolled in elementary schools participated in this study. The students' ages ranged from 7 to 15 years old $(M=10.3$; $S D=1.09)$. There were 266 students consisting of 110 female and 156 male students in the intervention group $(\mathrm{M}=10.3$; $\mathrm{SD}=1.11)$. The first control group had 214 students, 105 females and 109 males $(M=10.4$; $S D=1.19)$. The second control group had 330 students, 155 female and 175 males $(M=10.3 ; S D=0.999)$. Table 1 shows the characteristics of student participants.

The study used two control groups in an effort to detect latent bias (Lu \& Rosenbaum, 2004). The pretest values of psychological variables may differ depending on living and/or social circumstances of participants. An analysis of the pretest results showed significant differences between the three groups in depression and anxiety, but not in stress. Similar results are observed in the two control groups. These differences will clarify the actual influence of the program on the intervention group.

\subsection{Measures}

The negative emotional state of children was measured by the Depression, Anxiety, and Stress Scales (DASS 42) (Lovibond \& Lovibond, 1995). The 42-item questionnaire consists of three self-report scales. Each scale contains 14 items and is divided into subscales of 2 - 5 items with similar content. Dysphoria, hopelessness, devaluation of life, self-deprecation, and lack of interest/involvement, anhedonia, and inertia are assessed in the depression scale. The anxiety scale has indicators of autonomic arousal, musculo-skeletal effects, situational anxiety, and subjective experience of anxious affect. A chronic non-specific arousal scale assessed sensitivity to stress. Respondents are asked to use a 4-point severity scale to rate the extent to which they have experienced each symptom over the past week. Table 2 shows the severity rating index of DASS.

The DASS 42 was administered to 745 students in the fourth through sixth grades in Yogyakarta schools before any PE and sports programs began. We analyzed the validity and reliability of the DASS 42 for students in our sample. The analysis of internal validity verified that the DASS 42 was suitable for our sample $(p<0.01)$. A reliability test of the DASS 42 for children in this study yielded a Cronbach's alpha of 0.904 .

\subsection{Procedure}

The study was designed in three phases: planning, implementation, and evaluation. In the planning phase, we developed a PE and sports program for the intervention group. We administered the DASS 42 to measure negative emotional states of all students prior to the beginning of programs. The PE and sports program for the intervention group were based on psychosocial education practices that use physical activities in a group, problem solving and coping with stress, including holistic relaxation exercises. The intervention program was summarized

Table 1. Student characteristics for the intervention and control groups.

\begin{tabular}{ccccccccc}
\hline \multirow{2}{*}{ Group } & \multicolumn{3}{c}{ Age } & & Grade & & \multicolumn{2}{c}{ Sex } \\
\cline { 2 - 8 } & Mean & $\begin{array}{c}\text { Standard } \\
\text { Deviation }\end{array}$ & 4 th & 5 th & 6 th & F & M \\
\hline Intervention & 10.34 & 1.112 & 98 & 87 & 81 & 110 & 156 \\
Control 1 & 10.39 & 1.192 & 69 & 63 & 82 & 105 & 109 \\
Control 2 & 10.29 & .999 & 115 & 116 & 99 & 155 & 175 \\
\hline
\end{tabular}

Table 2. DASS symptom severity ratings (Lovibond \& Lovibond, 1995).

\begin{tabular}{cccc}
\hline & Depression & Anxiety & Stress \\
\hline Normal & $0-9$ & $0-7$ & $0-14$ \\
Mild & $10-13$ & $8-9$ & $15-18$ \\
Moderate & $14-20$ & $10-14$ & $19-25$ \\
Severe & $21-27$ & $15-19$ & $26-33$ \\
Extremely Severe & $28+$ & $20+$ & $34+$ \\
\hline
\end{tabular}


in handbooks and was accompanied with video supplements. PE and sports programs designed for the first and second control groups were based on existing curricula in each school. In the implementation phase, we conducted a special training for teachers of PE and sports assigned to the intervention group. The training incorporated theoretical, practical, and focus group discussions on psychosocial education, whereas PE and sports teachers in the first and second control groups were not provided additional training. Implementation of all programs occurred over 2 semesters (28 weeks). In the evaluation phase, we administered the DASS 42 to all students after the PE and sports programs concluded at the end of the year.

\subsection{Analysis}

Repeated measures analysis of variance (ANOVA) tested for differences between the intervention and control groups before and after the PE and sports programs. One-way ANOVA was used to compare the changes in negative emotional states (depression, anxiety, and stress) before and after PE and sports program across groups. Paired sample t-tests were used to evaluate differences within groups. Data analysis was performed using SPSS Version 22.0 for Windows.

\section{Results}

The groups had significantly different changes in depression states from pre-to post-intervention. There was a significant interaction of mean depression scores between test and groups $(\mathrm{F}(2,807)=4.182, \rho=0.016)$, and mean depression scores $(\mathrm{F}(2,807)=7.327, \rho=0.001)$ when the pre and post-test scores of groups are combined. The plot in Figure 1 shows the differences.

To compare the change in depression scores across groups, we performed a one-way ANOVA. Significant differences of depression states between groups were found $(\mathrm{F}(2,807)=4.182, \rho=0.016)$. There were significant differences in depression states between the intervention group and first control group $(\rho=0.005)$ and second control group $(\rho=0.040)$, however, there was no significant difference between control groups $(\rho=$ 0.325). Figure 2 shows the plots of mean depression differences between groups.

The differences of depression before and after PE and Sports programs within groups were assessed by using a paired-samples t-test. There was a significant reduction in depression after the psychosocial PE and sports program for the intervention group $(\mathrm{t}(265)=5.384 ; \rho=0.000)$. The second control group also showed a significant decrease in depression scores after their program $(\mathrm{t}(329)=2.420 ; \rho=0.016)$. There was no significant reduction in depression for the first control group ( $\mathrm{t}(213)=0.718 ; \rho=0.474)$. The intervention and second control groups showed decreased depression as a result of their respective programs. Results are summarized in Table 3.

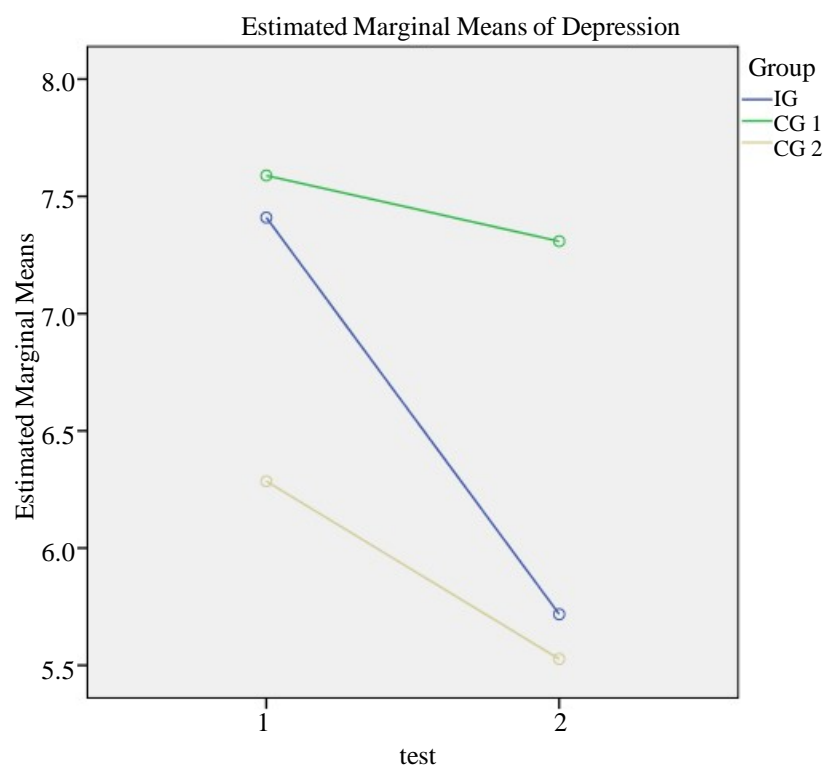

Figure 1. Comparison of depression states within and between group and test. 


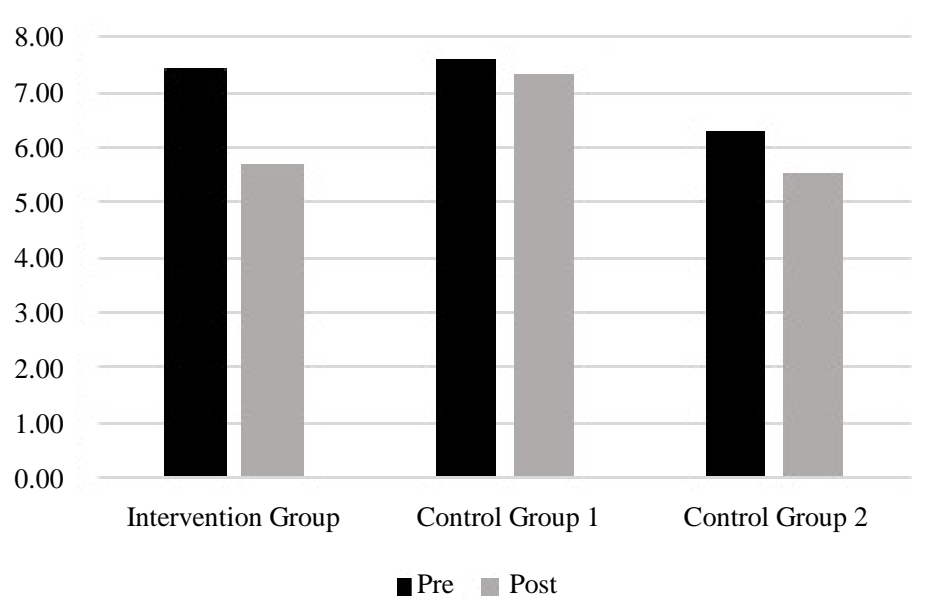

Figure 2. Mean depression score changes for groups.

Table 3. Paired-sample t-tests for depression.

\begin{tabular}{|c|c|c|c|c|c|c|}
\hline \multirow{2}{*}{ Group } & \multicolumn{2}{|c|}{ Mean } & \multicolumn{2}{|c|}{ Standard Deviation } & \multirow{2}{*}{$\mathrm{t}$} & \multirow{2}{*}{$\begin{array}{l}\text { Sig. } \\
\text { (2 tailed) }\end{array}$} \\
\hline & Pre & Post & Pre & Post & & \\
\hline Intervention & 7.41 & 5.72 & 5.934 & 5.393 & 5.384 & $0.000^{*}$ \\
\hline Control 1 & 7.59 & 7.31 & 5.443 & 5.621 & 0.718 & 0.474 \\
\hline Control 2 & 6.28 & 5.53 & 4.710 & 5.221 & 2.420 & $0.016^{*}$ \\
\hline
\end{tabular}

Note: ${ }^{*} \rho<0.025$.

There was a significant interaction between mean anxiety scores and groups $(\mathrm{F}(2,807)=5.110, \rho=0.006)$. The groups had significantly different changes in anxiety from pre-to post-programming $(\mathrm{F}(2,807)=9.358, \rho=$ 0.000). The plot in Figure 3 shows the differences.

To compare changes in anxiety scores across groups, a one-way ANOVA was performed. There were significant differences of anxiety states between groups $(F(2,807)=5.110, \rho=0.006)$. Significant differences in anxiety were found between the intervention group and the second control group $(\rho=0.002)$, but were not found between the intervention group and first control group $(\rho=0.064)$, or between the first and second control groups $(\rho=0.296)$. Figure 4 shows the plots of mean anxiety change between groups.

Paired-sample t-tests were performed to assess group differences in anxiety before and after the PE and sports program. There was a significant reduction of anxiety after the $\mathrm{PE}$ and sports program for the intervention group $(\mathrm{t}(265)=6.599 ; \rho=0.000)$ and first control group $(\mathrm{t}(213)=2.744 ; \rho=0.007)$. Anxiety was not significantly reduced for the second control group ( $\mathrm{t}(329)=1.723 ; \rho=0.086)$. Results are summarized in Table 4 .

There was the significant interaction of mean stress scores between test and groups $(\mathrm{F}(2,807)=7.631, \rho=$ 0.001). Mean stress scores are also significantly different when the pre-and post-tests of the group are combined $(\mathrm{F}(2,807)=4.216, \rho=0.015)$. The plot in Figure 5 summarizes these results.

To compare the change of stress scores across groups, we performed a one-way ANOVA. There were significant differences of stress states between the groups $(\mathrm{F}(2,807)=7.631, \rho=0.001)$. Significant differences appeared between the interventions and first control group $(p=0.000)$, as well as the second control group ( $\rho=$ 0.002). No significant differences were found between the first and second control groups $(\rho=0.746)$. Figure 6 shows the plots of mean stress differences between groups.

Paired-sample t-tests were performed to assess group differences in stress states before and after the PE and sports program. There was a significant reduction in anxiety after the $\mathrm{PE}$ and sports program for the intervention group $(\mathrm{t}(265)=8.250, \rho=0.000)$ and the second control group ( $(329)=3.322, \rho=0.001)$, but not for the first control group $(\mathrm{t}(213)=1.946, \rho=0.053)$. Results are summarized in Table 5.

\section{Discussion}

Analysis of the effects of PE and sports programs on depression showed significant interactions and differences 


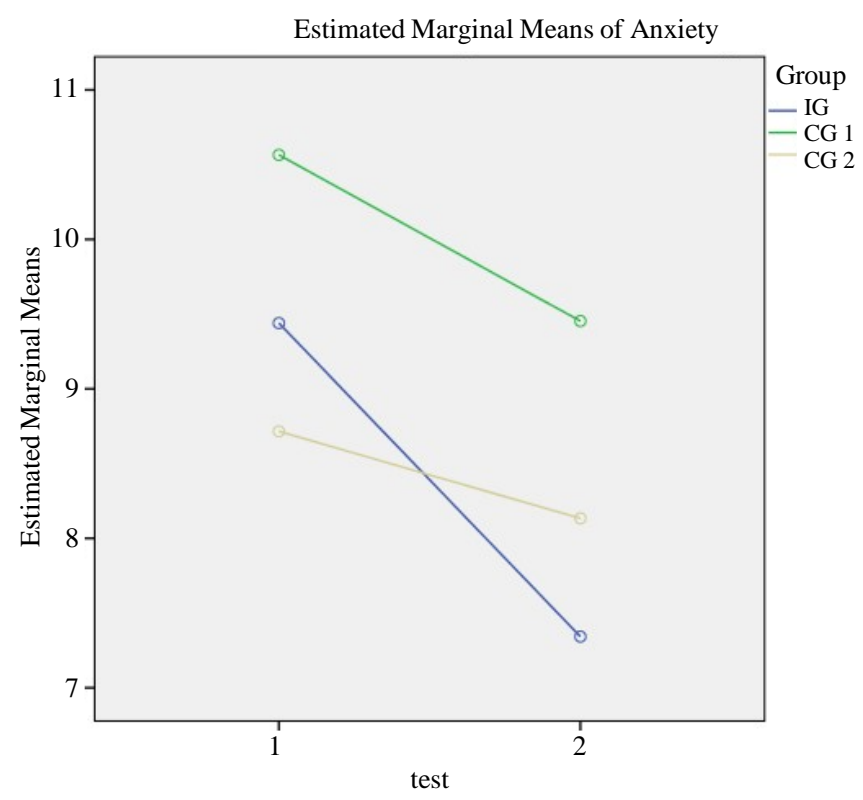

Figure 3. Comparison of anxiety within and between groups and test.

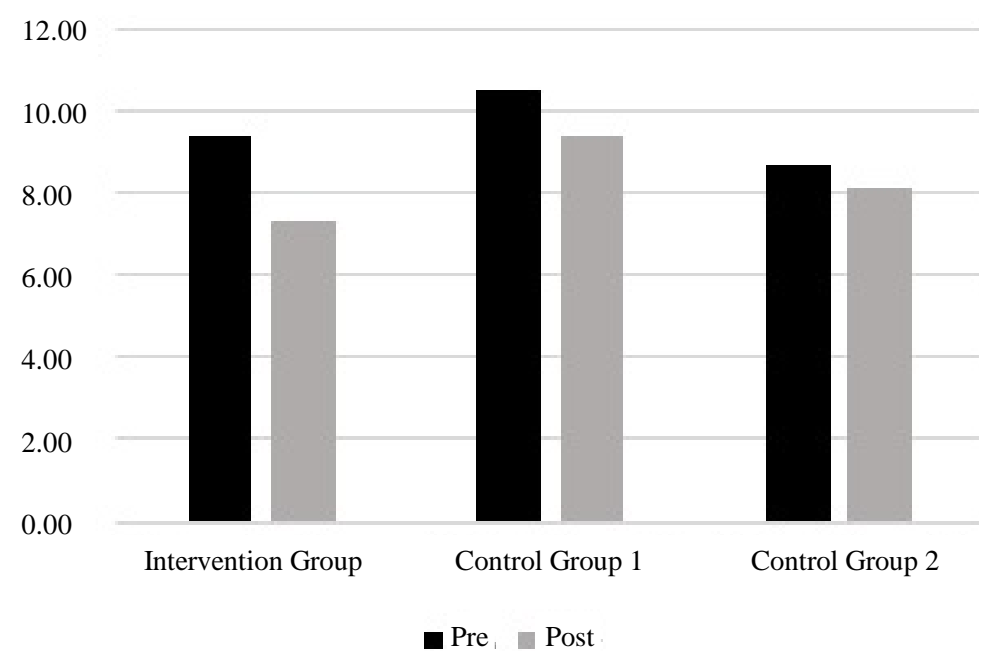

Figure 4. Mean anxiety changes in groups.

Table 4. Paired-sample t-tests for anxiety.

\begin{tabular}{ccccccc}
\hline Group & \multicolumn{2}{c}{ Mean } & \multicolumn{2}{c}{ Standard Deviation } & t & Sig. (2 tailed) \\
\hline Intervention & Pre & Post & Pre & Post & & $0.000^{*}$ \\
Control 1 & 9.44 & 7.34 & 5.518 & 4.876 & 6.599 & $0.004^{*}$ \\
Control 2 & 10.57 & 9.45 & 6.015 & 5.839 & 2.744 & 0.086 \\
\hline
\end{tabular}

Note: ${ }^{*} \rho<0.025$.

between groups. There was a significant reduction in depression for the intervention group $(\mathrm{M}=1.692)$ and second control group $(M=0.758)$, but not for the first control group $(M=0.280)$. The therapeutic psychosocial $\mathrm{PE}$ and sports program had a major impact on the decrease in depression for students in the intervention group. Our results are similar to the findings of Annesi (2005), confirming a significant reduction in depression for a 


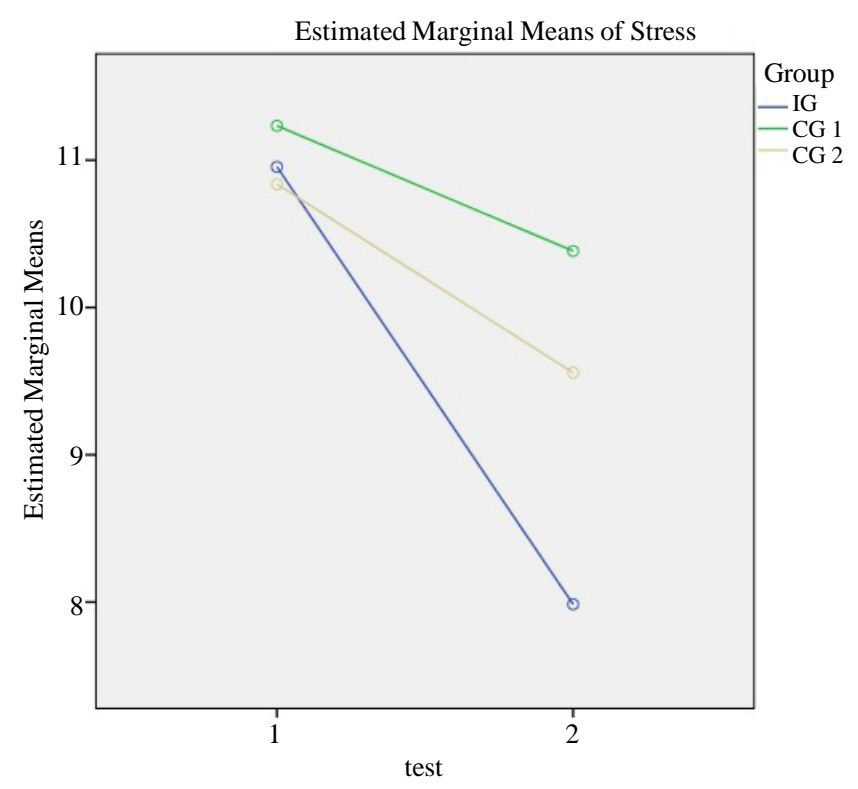

Figure 5. Comparison of stress within and between groups and test.

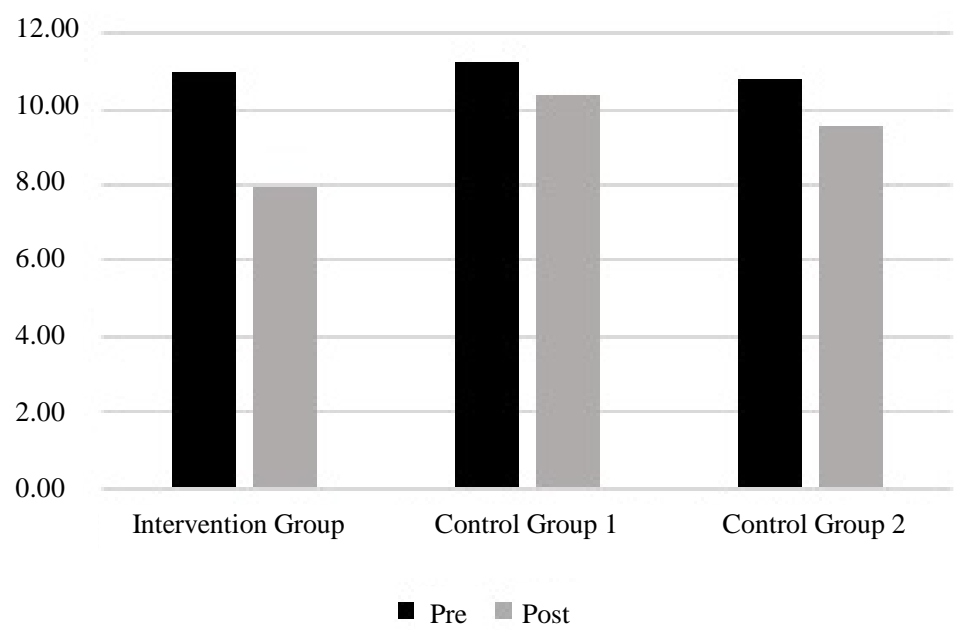

Figure 6. Mean stress differences between groups.

Table 5. Paired-sample t-tests for stress.

\begin{tabular}{cccccccc}
\hline \multirow{2}{*}{ Group } & \multicolumn{3}{c}{ Mean } & \multicolumn{2}{c}{ Standard Deviation } & \multirow{2}{*}{ S } & Sig. (2 tailed) \\
\cline { 2 - 6 } & Pre & Post & Pre & Post & & & $0.000^{*}$ \\
Intervention & 10.95 & 7.98 & 6.059 & 5.665 & & 8.250 & 0.053 \\
Control 1 & 11.23 & 10.38 & 6.096 & 5.861 & & 1.946 & $0.001^{*}$ \\
Control 2 & 10.84 & 9.56 & 5.888 & 6.382 & 3.322 & 0.302 \\
\hline
\end{tabular}

Note: ${ }^{*} \rho<0.025$.

treatment group engaged in physical activity compared to a control group who was getting no exercise. The decrease in depression is an important finding especially for children who have been traumatized after disasters (Aslam \& Tariq, 2010; Kolaitis, et al., 2011; Roussos, et al., 2005). Some research has found a significant reduction in depression in various training and exercise program (Camero, Hobss, Stringer, Branscum, \& Taylor, 2012; Motta, Kuligowski, \& Marino, 2010; Bicer, Asghari, Kharazi, \& Asl, 2012). It is the necessary role of PE and sports programs to lower depression so traumatized children can enjoy their daily lives again. Moghaddam, 
Mehrdad, Salehian, \& Shirmohammadzadeh (2012) have also demonstrated a significant reduction in students’ depression rates through participation in many sports like swimming, track and field, and football.

The analysis of the effect of PE and sports programs on anxiety showed significant interactions and differences between groups as well. A significant reduction in anxiety for the intervention group $(M=2.098)$ and first control group ( $M=1.112$ ) was found, but none was found for the second control group ( $M=0.582)$. The PE and sports programs of both the intervention and first control groups had a positive effect on the reduction of anxiety. $\mathrm{PE}$ and sports programs in the second control group did not have a positive impact on the reduction of anxiety state. Exercise has also been shown to be an effective treatment for anxiety (Moghaddam, Mehrdad, Salehian, \& Shirmohammadzadeh, 2012; Yildrim, 2012; Bicer, Asghari, Kharazi, \& Asl, 2012). According to many researchers, anxiety reduction is important for children who have experienced a disaster (Kar, 2009; Ronholt, Karsberg, \& Elklit, 2013; Uemoto, Asakawa, Takamiya, Asakawa, \& Inui, 2012).

The analysis of the effects of PE and sports programs on stress showed significant interactions and differences between and within groups. PE and sports programs in the intervention and second control groups had a positive effect on the reduction of stress. Moghaddam, Mehrdad, Salehian, \& Shirmohammadzadeh, (2012) support our findings that regular exercise reduces stress. Other researchers have found that developmentally appropriate physical activity in PE or an after-school program could affect basic psychological and somatic coping skills in stress reduction (Wahl-Alexander \& Sinelnikov, 2013; Ronan \& Johnson, 1999). Breathing exercises, such as yoga, were included in our psychosocial program have been supported by researchers as an effective intervention for stress reduction (Jellesma, 2013). Others have found that children in a disaster prone area would need sufficient skills to help support stress reduction and prevent other negative psychological symptoms (Uemoto, Asakawa, Takamiya, Asakawa, \& Inui, 2012; Yonekura, Ueno, \& Iwanaka, 2013).

\section{Conclusion}

A special therapeutic psychosocial PE and sports program was implemented as an intervention with a group of children in the Merapi volcano disaster-prone areas of Indonesia. A significant impact on negative emotional states (depression, anxiety, and stress) was supported as an outcome of this program. Control groups did not show a decrease in negative emotional states for all factors examined. Expectedly, the program to be the fundamental development of specialized physical education and sports curriculum for the school in disaster-prone areas. Although the program evaluation results were showed desirable results, there might be some possible weaknesses. Limitations included differences in the teaching abilities of teachers that might have had consequences in program implementation, possible differences in school policies for curricula in PE and sports, school infrastructure deficiencies, and differences in the application of the program itself.

\section{Acknowledgements}

The authors would like to extremely grateful to the principals, teachers, and students were involved in this study. Special thanks to the DGHE scholarship to provide a study abroad opportunity. This work was also supported by KAKENHI Grant Number 24500704.

\section{References}

Annesi, J. J. (2005). Correlations of Depression and Total Mood Disturbance with Physical Activity and Self-Concept in Preadolescents Enrolled an After-School Exercise Program. Psychological Report, 96, 891-898. http://dx.doi.org/10.2466/PR0.96.3.891-898

Aslam, N., \& Tariq, N. (2010). Trauma, Depression, Anxiety, and Stress among Individuals Living in Earthquake Affected and Unaffected Areas. Pakistan Journal of Psychological Research, 25, 131-148.

Bicer, S. Y., Asghari, A., Kharazi, P., \& Asl, N. S. (2012). The Effect of Exercise on Depression and Anxiety of Students. Annals of Biological Research, 3, 270-274. http://scholarsresearchlibrary.com/archive.html

Camero, M., Hobss, C., Stringer, M., Branscum, P., \& Taylor, E. L. (2012). A Review of Physical Activity Interventions on Determinants of Mental Health in Children and Adolescents. International Journal of Mental Health Promotion, 14, 196-206. http://dx.doi.org/10.1080/14623730.2012.752901

Curelaru, M., Abalasei, B., \& Cristea, M. (2011). Psychosocial Correlates of the Need for Physical Education and Sports in High School. Journal of Social Sciences, 7, 521-528. http://dx.doi.org/10.3844/jssp.2011.521.528

Henley, R. (2005). Helping Children Overcome Disaster Trauma through Post Emergency Psychosocial Sports Program. 
Boezingenstrasse: Swiss Academy for Development.

Henley, R., Schweizer, I. C., de Gara, F., \& Vetter, S. (2007). How Psychosocial Sport \& Play Programs Help Youth Manage Adversity: A Review of What We Know \& What We Should Research. International Journal of Psychosocial Rehabilitation, 12, 51-58.

Jellesma, F. C. (2013). Stress and Yoga in Children. Journal of Yoga and Physical Theraphy, 3, 1-3. http://dx.doi.org/10.4172/2157-7595.1000136

Jogia, J., Kulatunga, U., Yates, G. P., \& Wedawatta, G. (2014). Culture and the Psychological Impacts of Natural Disasters: Implications for Disaster Management and Disaster Mental Health. The Built \& Human Environment Review, 7, 1-10.

Kar, N. (2009). Psychological Impact of Disaster on Children: Review of Assesment and Interventions. World Journal of Pediatric, 5, 5-11. http://dx.doi.org/10.1007/s12519-009-0001-x

Kilic, E. Z., Ozguven, H. D., \& Sayil, I. (2003). The Psychological Effects of Parental Mental Health on Children Experiencing Disaster: The Experience of Bolu Earthquake in Turkey. Family Process, 42, 485-495.

http://dx.doi.org/10.1111/j.1545-5300.2003.00485.x

Kolaitis, G., Giannakopoulos, G., Mihas, C., Ntre, V., Moulla, V., Sotiropoulou, E., et al. (2011). Symptoms of Posttraumatic Stress, Depression, and Anxiety among Youths Exposed to a Massive Fire Disaster in Greece. British Journal of Medicine \& Medical Research, 1, 320-332. http://dx.doi.org/10.9734/BJMMR/2011/505

Lavigne, F., De Coster, B., Juvin, N., Flohic, F., Gaillard, J.-C., Texier, P., et al. (2008). People’s Behavior in the Face of Volcanic Hazards: Perpspectives from Javanese Communities, Indonesia. Journal of Volcanology and Geothermal Research, 172, 273-287. http://dx.doi.org/10.1016/j.jvolgeores.2007.12.013

Lovibond, S. H., \& Lovibond, P. F. (1995). Manual for the Depression Anxiety Stress Scales Second Edition. Sydney: Psychology Foundation.

Lu, B., \& Rosenbaum, P. R. (2004). Optimal Pairing Matching with Two Control Groups. Journal of Computational and Graphical Statistic, 13, 422-434. http://dx.doi.org/10.1198/1061860043470

Moghaddam, J. B., Mehrdad, H., Salehian, M. H., \& Shirmohammadzadeh, M. (2012). Effects of Different Exercise on Reducing Male Students Depression. Annals of Biological Research, 3, 1231-1235. http://scholarsresearchlibrary.com/archive.html

Mondal, R., Sarkar, S., Banerjee, I., Hazra, A., Majumber, D., Sabui, T., et al. (2013). Acute Stress-Related Psychological Impact in Children Following Devastating Natural Disaster, the Sikkim Earthquake (2011) India. Journal of Neuorsciences in Rural Practice, 4, 19-23. http://dx.doi.org/10.4103/0976-3147.116434

Motta, R. W., Kuligowski, J. M., \& Marino, D. M. (2010). The Role of Exercise in Reducing Childhood and Adoloscent PTSD, Anxiety, and Depression. NASP Communique, 38, 24-29.

Mutohir, T. C. (2015). Improving the Quality of Physical Educatioan and Sport in an Indonesian Education Setting. Proceedings of 4th International Conference of Physical Education and Sports Science 2015 (pp. 17-19). Jakarta: Universitas Negeri Jakarta.

Piko, B. F., \& Kereztes, N. (2006). Physical Activity, Psychosocial Health and Life Goals among Youth. Journal of Community Health, 31, 136-145. http://dx.doi.org/10.1007/s10900-005-9004-2

Ronan, K. R., \& Johnston, D. M. (1999). Behaviorally-Based Interventions for Children Following Volcanic Eruptions: An Evaluation of Effectiveness. Disaster Prevention and Management, 8, 169-176. http://dx.doi.org/10.1108/09653569910275364

Ronholt, S., Karsberg, S., \& Elklit, A. (2013). Preliminary Evidence for a Classroom Based Psychosocial Intervention for Disaster Exposed Children with Posttraumatic Stress Symptomatology. Child Youth Care Forum, 42, 617-631. http://dx.doi.org/10.1007/s10566-013-9220-3

Roussos, A., Goenjian, A., Steinberg, A., Sotiropoulou, C., Marina, K., Kabasko, C., et al. (2005). Posttraumatic Stress and Depressive Reactions among Children and Adoloscents after the 1999 Earthquake in Ano Liosia, Greece. The American Journal of Psychiatry, 162, 530-537. http://dx.doi.org/10.1176/appi.ajp.162.3.530

Uemoto, M., Asakawa, A., Takamiya, S., Asakawa, K., \& Inui, A. (2012). Kobe Earthquake and Post-Traumatic Stress in School-Aged Children. International Journal of Behavior and Medicine, 19, 243-251. http://dx.doi.org/10.1007/s12529-011-9184-3

Wahl-Alexander, Z., \& Sinelnikov, O. A. (2013). Using Physical Activity for Emotional Recovery after a Natural Disaster. Journal of Physical Education, Recreation \& Dance, 84, 23-28. http://dx.doi.org/10.1080/07303084.2013.767729

Yildrim, E. (2012). The Effect of Exercise Program of Self-Concept, Anxiety, and Antisocial Beahvior Male and Female Students. Annals of Biological Research, 3, 3305-3311. http://scholarsresearchlibrary.com/archive.html

Yonekura, T., Ueno, S., \& Iwanaka, T. (2013). Care of Children in a Natural Disaster: Lesson Learned from the Great East Japan Earthquake and Tsunami. Pediatric Surgery International, 29, 1047-1051.

http://dx.doi.org/10.1007/s00383-013-3405-6 